\title{
RELAÇÕES RADIOMÉTRICAS NO TERÇO SUPERIOR DA COPA DE CAFEEIRO $\left({ }^{1}\right)$
}

\author{
ANTONIO RIBEIRO DA CUNHA $\left({ }^{* *}\right)$; CLOVIS ALBERTO VOLPE $\left({ }^{3}\right)$
}

\begin{abstract}
RESUMO
Com o objetivo de obter os coeficientes de transmissão e de extinção da radiação fotossinteticamente ativa determinou-se o índice de área foliar e mediu-se a radiação fotossinteticamente ativa transmitida no terço superior da copa de cafeeiro variedade Obatã IAC 1669-20, com três diferentes alinhamentos de plantio, em função da trajetória aparente do Sol, em Jaboticabal (SP). Foram três tratamentos, com quatro repetições, no total de doze parcelas, e cada uma com cem cafeeiros; cada tratamento correspondeu a um alinhamento de plantio. $\mathrm{O}$ alinhamento $81^{\circ}-261^{\circ}$, por ser o que mais se aproximava do movimento aparente do Sol desde o nascente até o poente, favoreceu um autossombreamento maior na linha, e assim, ocorre maior disponibilidade de radiação solar difusa, contribuindo para maior índice de área foliar. Os coeficientes de transmissão são menores e os de atenuação são maiores para o alinhamento $81^{\circ}-261^{\circ}$, revelando maior eficiência na interceptação da radiação fotossinteticamente ativa no terço superior da copa desse alinhamento. Foi possível estimar o coeficiente de extinção $\left(k_{R F A}\right)$ em função do índice de área foliar (IAF) por meio do modelo exponencial: $\kappa_{R F A}=A+B^{*} \exp (-I A F / C)$; e estimar o índice de área foliar em função da radiação fotossinteticamente ativa interceptada (RFAint) pelo modelo polinomial quadrático: $I A F=A(\text { RFAint })^{2}+B($ RFAint $)+C$, onde $A, B$ e $C$ são parâmetros dos modelos.
\end{abstract}

Palavras-chave: Coffea arabica L., índice de área foliar, radiação fotossinteticamente ativa, coeficientes de transmissão e extinção, modelagem.

\section{ABSTRACT \\ RADIOMETRIC RELATIONS IN UPPER THIRD OF THE CANOPY OF THE COFFEE TREE}

The transmission coefficients and extinction of photosynthetically active radiation were obtained from measurements the of leaf area index and of the photosynthetically active radiation intercepted in the upper third of the canopy of coffee tree var. Obatã IAC 1669-20 with three different alignments of planting according to the apparent path of the Sun, in Jaboticabal, São Paulo State, Brazil. There were three treatments with four repetitions, a total of twelve plots, each containing one hundred coffee trees, and each treatment corresponded to an alignment of planting. The alignment $81^{\circ}-261^{\circ}$ was the closest to the Sun's apparent movement throughout the day, allowing self-shading greater in the line and availability greater of diffuse solar radiation, contributing to a greater leaf area index. The alignment $81^{\circ}-261^{\circ}$ presented the lower transmission coefficient and greater of attenuation, showing up more efficient in interception of photosynthetic active radiation in the upper third of the canopy of this alignment. The extinction coefficient $\left(k_{P A R}\right)$ was estimated as a function of leaf area index $(L A I)$ by means of the exponential model: $\kappa_{P A R}=A+B^{*} \exp (-L A I / C)$; and the leaf area index was estimated as a function of photosynthetically active radiation intercepted (PARint) by the quadratic polynomial model: $L A I=A(P A R \text { int })^{2}+B(P A R$ int $)$ $+C$, where $A, B$ and $C$ are parameters of the models.

Key words: Coffea arabica L., leaf area index, photosynthetically active radiation, transmission coefficients and extinction, modeling.

( $\left.{ }^{1}\right)$ Recebido para publicação em 14 de agosto de 2008 e aceito em 24 de novembro de 2009.

( $\left.{ }^{2}\right)$ Departamento de Recursos Naturais, FCA-UNESP, Caixa. Postal 237, 18610-307 Botucatu (SP). E-mail:arcunha@fca.unesp.br (*) Autor correspondente.

$\left({ }^{3}\right)$ In memoriam. 


\section{INTRODUÇÃO}

As radiações eletromagnéticas, cujos comprimentos de ondas são capazes de provocar uma reação fotoquímica na folha vegetal são denominadas de radiação fotossinteticamente ativa (RFA), as quais são importantes na conversão da energia solar incidente em energia química para a produção de fitomassa (Gliessman, 2000). Da radiação solar recebida pela superfície da Terra, em média, $44 \%$ ocorre em comprimentos de onda úteis para a fotossíntese. Mesmo as espécies de plantas mais eficientes somente incorporam de 3\% a 10\% dessa radiação à sua produção de fitomassa (FrEITAS, 2005).

A eficiência fotossintética de uma copa é afetada pela taxa fotossintética por unidade de área foliar e pela forma como a radiação solar é interceptada, pois esta interceptação altera o balanço de radiação e de energia, e depende das características da copa, ou seja, sua arquitetura e dimensão (BeninCASA, 1988; GALlo et al., 1993; BERNARDES et al., 1996).

O cafeeiro adulto possui uma arquitetura adequada para a interceptação da luz. Ele utiliza de $40 \%$ a $54 \%$ de sua produção total de matéria seca para incrementar a nova área foliar. Plantas com espaçamentos adensados produzem dosséis com boas características de transmissão de luz, galhos superiores com ângulos pequenos em relação à vertical, folhas distribuídas em grandes distâncias verticais e estruturas cônicas, fazendo com que o dossel receba uma sombra moderada, sendo uma necessidade, visto que as folhas do cafeeiro têm sua máxima fotossíntese a baixas intensidades de radiação (CANNELL, 1976).

A transmissão da RFA em uma comunidade de plantas, de acordo com a lei de Beer, é uma função exponencial negativa do produto do índice de área foliar (IAF) pelo coeficiente de extinção $\left(\mathrm{k}_{\mathrm{RFA}}\right)$, que depende das propriedades óticas das folhas e do dossel vegetativo, sendo assim, necessário medidas de área foliar no dossel acima do sensor de RFA para a determinação da interceptação dessa radiação (SCHÖFFEl e VOLPE, 2001).

O plantio adensado e orientado na linha de plantio, em comparação com o plantio tradicional de cafeeiros, pode alterar a incidência de radiação solar no interior das plantas. Para melhor eficiência no aproveitamento da radiação solar e, consequentemente, obter uma luminosidade mais adequada para o crescimento e desenvolvimento do cafeeiro, FERNANDEs et al. (2001) recomendam mais estudos para encontrar a melhor orientação de plantio das linhas de cafeeiro adulto, pois a grande maioria dos trabalhos estudam a irradiância em cafeeiros jovens cultivados em vasos.
Este trabalho teve como objetivo estimar os coeficientes de transmissão e extinção da radiação fotossinteticamente ativa no terço superior da copa de cafeeiros adensados e em três diferentes alinhamentos de plantio.

\section{MATERIAL E MÉTODOS}

O experimento foi implantado em Jaboticabal, SP (latitude: $21^{\circ} 14^{\prime} 05^{\prime \prime}$ S; longitude: $48^{\circ} 17^{\prime} 09^{\prime \prime} \mathrm{W}$; e altitude: $615 \mathrm{~m}$ ) em uma cultura de cafeeiro var. Obatã IAC 1669-20, com 5 anos de idade, altura média de $2 \mathrm{~m}$ e espaçamento de $3,5 \times 0,5 \mathrm{~m}$.

O plantio do cafeeiro foi feito em 13/7/2001. Foram definidos três alinhamentos de plantio para o cafeeiro em função de três estádios fenológicos: 1) vegetação plena $(15 / 1)$; 2) maturação dos frutos (15/ 5); e 3) floração e enchimento dos grãos (15/09), sendo essas épocas definidas com base nos estádios fenológicos descritos por CAMARGo e CAMARGo (2001). Esses três alinhamentos do cafeeiro foram calculados mediante a determinação da posição do Sol em certo instante, em dado local e data, a partir do ângulo zenital e do azimute do Sol, sendo o ângulo zenital dependente da latitude local, declinação solar e do ângulo horário.

Para os cálculos, adotou-se o horário das $9 \mathrm{~h}$, pois o cafeeiro é uma planta C3, mas comporta-se como uma $\mathrm{C} 4$ por sua alta produtividade a pleno Sol, o que permite o aumento da fotossíntese líquida em função de incremento na irradiância a partir desse horário (Jones, 1994). A partir das 9h o Sol estará em uma posição formando um ângulo horário de $45^{\circ} \mathrm{com}$ um ponto referencial da Terra para uma dada latitude e data, indicando o deslocamento máximo angular que o Sol pode ter para haver maior disponibilidade de radiação solar naquele ponto.

Como o ângulo zenital é quem determina a posição do Sol em relação ao plano vertical local, foi possível determinar o ângulo no plano horizontal entre a projeção do raio do Sol e o ponto cardeal N-S, para calcular os alinhamentos.

Na tabela 1 observa-se o ângulo horário, a declinação do Sol, o ângulo zenital e o azimute, sendo este último que caracteriza o alinhamento para cada uma das datas definidas.

Com isso, foi possível instalar na área experimental os três alinhamentos de plantio do cafeeiro: $81^{\circ}-261^{\circ}(15 / \mathrm{jan}), 51^{\circ}-231^{\circ}\left(15 /\right.$ mai) e $66^{\circ}-246^{\circ}$ (15/set), sendo que cada alinhamento corresponde ao tratamento com quatro repetições, em um total de 12 parcelas, com cem cafeeiros em cada uma, segundo esquema na figura 1 . 
Tabela 1. Valores obtidos do ângulo horário, declinação do Sol, ângulo zenital e azimute para a localidade de Jaboticabal (SP)

\begin{tabular}{lcccc}
\hline Data & Ângulo horário $(\mathrm{h})$ & Declinação do Sol $(\mathrm{d})$ & Ângulo Zenital $(\mathrm{Z})$ & Azimute $(\mathrm{a})$ \\
\hline 15 de janeiro & $45^{\circ}$ & $21,3^{\circ} \mathrm{S}$ & $41,8^{\circ}$ & $81,4^{\circ}-261,4^{\circ}$ \\
15 de maio & $45^{\circ}$ & $18,7^{\circ} \mathrm{N}$ & $59,5^{\circ}$ & $51^{\circ}-231^{\circ}$ \\
15 de setembro & $45^{\circ}$ & $2,2^{\circ} \mathrm{N}$ & $50,5^{\circ}$ & $66^{\circ}-246^{\circ}$ \\
\hline
\end{tabular}

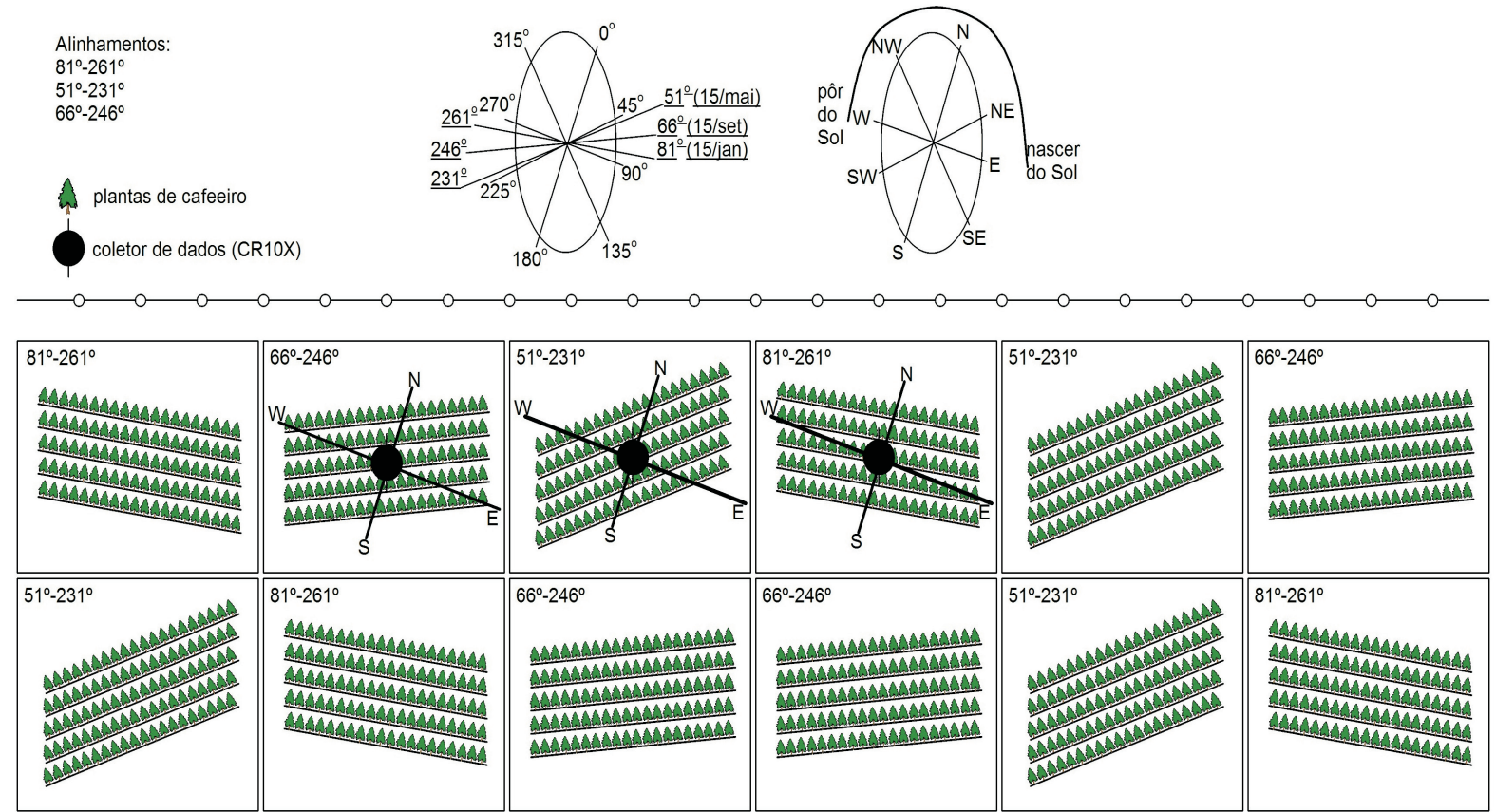

Figura 1. Representação esquemática da distribuição dos alinhamentos, destacando a linha central dos 3 alinhamentos onde foram feitas as medidas de AF e RFA na copa de uma planta de cafeeiro.

Foram utilizados sensores modelo PAR LITE (Kipp \& Zonen) quântico para as medidas de radiação fotossinteticamente ativa (RFA), que fornece a densidade de fluxo em $\mathrm{mmol} \mathrm{m} \mathrm{m}^{-2}$ e transformada para $\mathrm{W} \mathrm{m}^{-2}$ e depois integrada ao longo do dia em MJ $\mathrm{m}^{-2}$, segundo a relação: $1 \mathrm{~W} \mathrm{~m}^{-2}$ corresponde a 4,6 $\mu \mathrm{mol} \mathrm{s}{ }^{-1} \mathrm{~m}^{-2}$. As medidas de RFA acima do dossel foram obtidas em Estação Agroclimatológica, e a do cafeeiro, no terço superior da copa de uma planta representativa da linha central em cada um dos três alinhamentos apenas com uma repetição, sendo a medida obtida acima da visada do sensor em uma altura aproximada de $1,35 \mathrm{~m}$ acima da superfície do solo. Os sensores de RFA foram conectados ao coletor de dados CR10X da Campbell Scientific, com varredura a cada 1 minuto e armazenamento a cada 10 minutos.

Tendo em vista a dificuldade encontrada em medir-se a área foliar total de um cafeeiro, que com o crescimento aumenta a interferência de folhas superiores sobre as folhas inferiores da planta (autossombreamento), utilizou-se uma amostragem no terço superior da copa do cafeeiro para as medidas de área foliar (AF) acima da visada de um sensor de RFA, pois a irradiância interceptada varia ao longo da copa, e as folhas superiores apresentam maiores inclinações que as inferiores, o que acarreta maior interceptação da energia radiante por unidade de área (ARAújo, 2006), definindo-se então o terço superior do cafeeiro para essas relações, visto que é a parte da planta com maior atividade fotossintética.

Em 31/10/2006 foram coletadas cem folhas, de tamanho e forma variados, do terço superior da copa de cafeeiro dos três alinhamentos (tratamentos). Mediuse o comprimento (C) e a largura (L) dessas folhas com régua, e a $\mathrm{AF}$ com um integrador de área modelo Area Measurement System (Delta-T Devices LTD, Burwell Cambridge England). No fim, por meio de regressão linear simples obteve-se a equação de estimativa da $\mathrm{AF}$ em função das dimensões foliares: $\mathrm{AF}=0,7234^{*} \sum\left(\mathrm{C}^{*} \mathrm{~L}\right)$. Posteriormente, essa equação foi usada para a determinação da AF por medidas não-destrutivas das dimensões foliares no período vegetativo do cafeeiro, nas datas de 16/11/2006, 4/12/2006, 20/12/2006, 10/1/2007, 13/2/2007, 28/2/2007 e 15/3/2007, em intervalos variáveis de 15 até 34 dias. 
No momento destas medidas, efetuou-se a amostragem em uma planta representativa de cada alinhamento por meio de um delimitador de volume com a forma de paralelepípedo de área basal de $0,1024 \mathrm{~m}^{2}$, e com uma altura aproximada de $0,67 \mathrm{~m}$ (terço superior da copa), medindo-se o comprimento e a largura de todas as folhas contidas neste volume $\left(0,0686 \mathrm{~m}^{3}\right)$ responsáveis pela interceptação da RFA no terço superior da copa, sempre na mesma planta e no mesmo ponto acima da visada do sensor da RFA.

Utilizando-se a equação de estimativa da $\mathrm{AF}$ obtida em função das dimensões foliares, determinouse a AF das folhas contidas no delimitador nas datas de amostragem. Em seguida, a partir do volume do delimitador e de um cone com um volume proporcional ao terço superior da copa do cafeeiro $\left(0,1422 \mathrm{~m}^{3}\right)$ com diâmetro de $0,90 \mathrm{~m}$ e altura de 0,67 $\mathrm{m}$, foi possível estimar a AF do terço superior da copa do cafeeiro em função da relação direta e proporcional entre os volumes dos sólidos, e com isso, a partir da AF do terço superior da copa, determinou-se o índice de área foliar para um dos alinhamentos.

A partir da transmissão da RFA medida por meio de sensor quântico (RFAt), calculou-se o coeficiente de extinção dessa radiação $\left(k_{R F A}\right)$ para cada alinhamento segundo a equação:

$$
k_{R F A}=-\frac{\ln \left(\frac{R F A t}{R F A I}\right)}{I A F}
$$

onde RFAt e RFAI são valores de radiação fotossinteticamente ativa transmitida abaixo do terço superior da copa e a incidente acima do dossel, respectivamente em $\mathrm{MJ} \mathrm{m}^{-2}$.

A RFA interceptada (RFAint) no terço superior da copa foi calculada pela diferença entre a RFAI e a RFAt nos três alinhamentos, conforme a expressão:

$$
R F A \text { int }=R F A I-R F A t
$$

A partir da razão entre a RFA transmitida abaixo do terço superior da copa (RFAt) e a radiação fotossinteticamente ativa incidente no topo acima do dossel (RFAI), determinou-se a variação da transmissividade ou coeficiente de transmissão ( $\left.t_{R F A}\right)$ no terço superior da copa para os três alinhamentos, segundo a expressão:

$$
t_{R F A}=\frac{R F A t}{R F A I}
$$

sendo RFAI e RFAIo valores de radiação fotossinteticamente ativa transmitida abaixo do terço superior da copa e a incidente acima do dossel.
Um modelo de decaimento exponencial foi ajustado para estimar o $\mathrm{k}_{\mathrm{RFA}}$ em função do IAF para os três alinhamentos:

$$
k_{R F A}=A+B^{*} \exp \left(\frac{-I A F}{C}\right)
$$

sendo $A, B$ e $C$ os parâmetros do modelo.

Para estimar o IAF em função da RFAint acumulada, ajustou-se a um modelo polinomial quadrático, para os três alinhamentos:

$$
I A F=A(\text { RFAint })^{2}+B(\text { RFAint })+C
$$

sendo $A, B$ e $C$ os parâmetros do modelo.

\section{RESULTADOS E DISCUSSÃO}

A figura 2 representa a relação entre a área foliar (AF) medida e o produto do comprimento pela largura de cem folhas coletadas e medidas no terço superior da copa do cafeeiro, a qual deu origem à equação linear simples partindo da origem. A equação é adequada para a estimativa da $\mathrm{AF}$, com um coeficiente de determinação alto, um erro da ordem de $5 \%$, representando $72,34 \%$ do retângulo obtido pelo produto comprimento e largura nas folhas de cafeeiro, podendo o valor 0,7234 ser chamado de fator de forma das folhas de cafeeiro var. Obatã.

Em função das medidas lineares da folha de cafeeiro, vários pesquisadores constataram fatores de forma com valores próximos e com altos coeficientes de determinação nas estimativas da AF, tais como: 0,667 por Huerta e Alvim (1962), BARROS et al. (1973) e TAVARES JUNIOR et al. (2002), 0,703 por MARIN et al. (2003) 0,70 por Silva e VOLPE (2005), 0,6123 por PARTelli et al. (2006), e 0,6626 por Pompelli (2008).

Nas tabela 2 verifica-se a AF do terço superior da copa de cafeeiro nas diferentes datas de amostragem. $\mathrm{O}$ alinhamento $51^{\circ}-231^{\circ}$ foi aquele com menor AF média $\left(1,2723 \mathrm{~m}^{2}\right)$, seguido pelos alinhamentos $66^{\circ}-246^{\circ}\left(1,3262 \mathrm{~m}^{2}\right)$ e $81^{\circ}-261^{\circ}(1,4518$ $\mathrm{m}^{2}$ ). Observou-se em condições de campo, que os alinhamentos $51^{\circ}-231^{\circ}$ e $66^{\circ}-246^{\circ}$ foram semelhantes visualmente, com valores próximos de $\mathrm{AF}$.

A Figura 3 representa a variação do índice de área foliar (IAF) do terço superior da copa de cafeeiro. Nota-se aumento gradativo do IAF em função do período vegetativo do cafeeiro para todos os alinhamentos. Como o IAF é determinado em função da $\mathrm{AF}$, a proporção e as diferenças entre as orientações se mantém, e portanto, o alinhamento $51^{\circ}-231^{\circ}$ foi aquele com menor IAF $(2,0)$, seguido dos alinhamentos $66^{\circ}-246^{\circ}(2,1)$ e $81^{\circ}-261^{\circ}(2,3)$. MARIN et 
al. (2003) verificaram para a cultivar Mundo Novo Apuatã com 4 anos de idade e altura de 1,80 m, para as camadas que englobam o terço superior da copa de cafeeiro, valores de IAF entre 1,2 e 2,9.

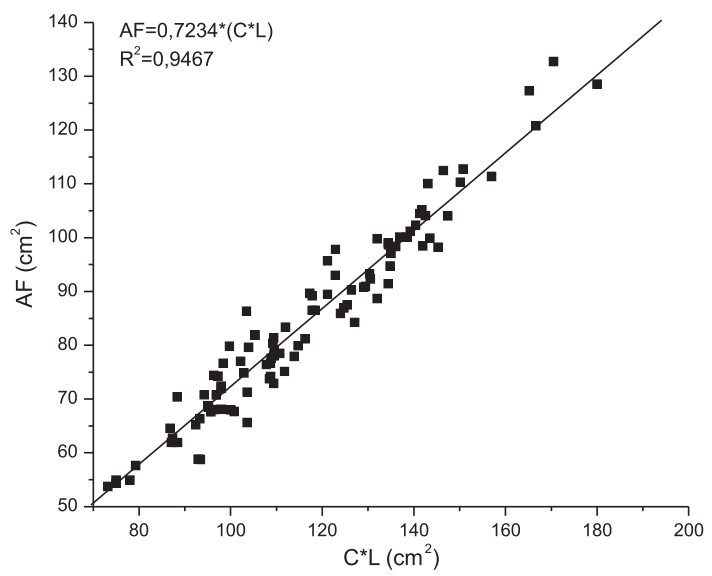

Figura 2. Relação entre a área foliar (AF) medida e o produto do comprimento pela largura $\left(C^{*} \mathrm{~L}\right)$ de 100 folhas coletadas e medidas no terço superior da copa de cafeeiro var. Obatã.

Tabela 2. Área foliar $\left(\mathrm{m}^{2}\right)$ estimada no terço superior da copa de cafeeiro var. Obatã

\begin{tabular}{lccc}
\hline Data & \multicolumn{3}{c}{ Alinhamentos } \\
\cline { 2 - 4 } & $66^{\circ}-246^{\circ}$ & $51^{\circ}-231^{\circ}$ & $81^{\circ}-261^{\circ}$ \\
\hline $16 / 11 / 06$ & 0,83 & 0,7854 & 0,9508 \\
$04 / 12 / 06$ & 1,08 & 0,9956 & 1,1971 \\
$20 / 12 / 06$ & 1,27 & 1,2014 & 1,5178 \\
$10 / 01 / 07$ & 1,46 & 1,3988 & 1,5920 \\
$13 / 02 / 07$ & 1,50 & 1,4647 & 1,6090 \\
$28 / 02 / 07$ & 1,55 & 1,5178 & 1,6131 \\
$15 / 03 / 07$ & 1,60 & 1,5431 & 1,6832 \\
\hline Média & 1,3262 & 1,2723 & 1,4518 \\
\hline
\end{tabular}

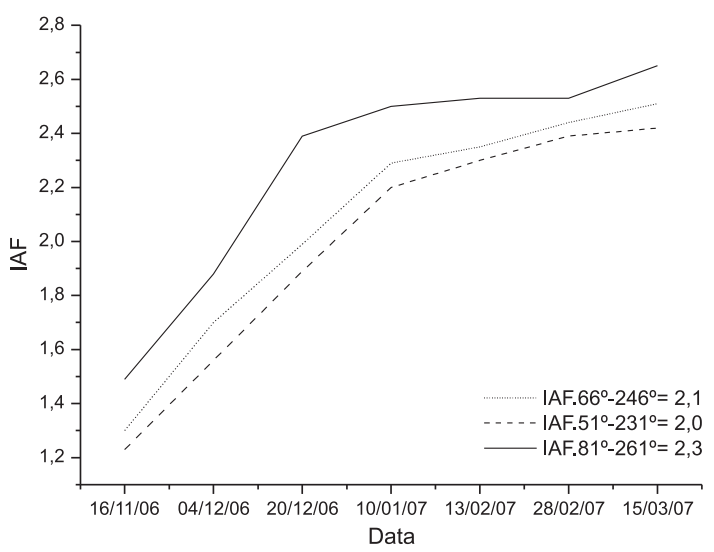

Figura 3. Variação do índice de área foliar (IAF) no terço superior da copa de cafeeiro var. Obatã nos alinhamentos $66^{\circ}-246^{\circ}, 51^{\circ}-231^{\circ}$ e $81^{\circ}-261^{\circ}$.
Observa-se na figura 4, um dia com insolação de 10,4 horas, considerado com céu límpido. Em média, os alinhamentos $66^{\circ}-246^{\circ}\left(3,2 \mathrm{MJ} \mathrm{m}^{-2}\right)$ e $51^{\circ}$ $231^{\circ}\left(4,0 \mathrm{MJ} \mathrm{m}^{-2}\right)$ transmitiram mais radiação fotossinteticamente ativa transmitida abaixo do terço superior da copa (RFAIt) ao longo do dia, ocorrendo o contrário com o alinhamento $81^{\circ}-261^{\circ}\left(1,2 \mathrm{MJ} \mathrm{m}^{-2}\right)$, em relação à radiação fotossinteticamente ativa incidente acima do dossel (RFAI) $\left(12,4 \mathrm{MJ} \mathrm{m}^{-2}\right)$. Observou-se picos de RFAt entre $10 \mathrm{~h} 30 \mathrm{~min}$ e $12 \mathrm{~h} 30 \mathrm{~min}$, os quais ocorreram em todos os alinhamentos, sendo devido ao ângulo de incidência da RFAI nesses horários associado às posições das folhas. Segundo DAMATTA (2003), quanto mais vertical estiver a folha de cafeeiro, menor será a interceptação da RFAI nas horas de maior elevação solar. Interessante notar que no período da manhã, até as 12h, a quantidade da RFAt foi maior para todos os alinhamentos, indicando que na face $\mathrm{N}$ das três orientações havia IAF maior em relação à face $S$ associado ao ângulo de incidência da radiação solar, pois houve maior interceptação no período da tarde provavelmente pela camada mais espessa de folhas que bloqueava a irradiância.

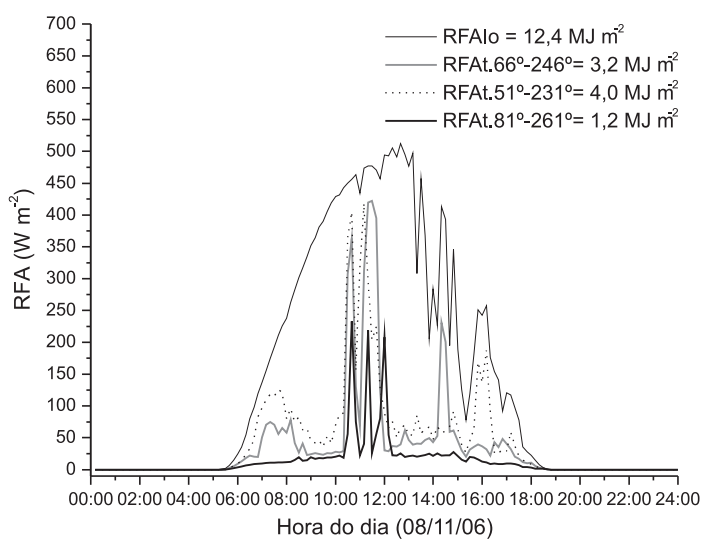

Figura 4. Radiação fotossinteticamente ativa incidente acima do dossel (RFAI) e transmitida no terço superior (RFAt) da copa de cafeeiro nos alinhamentos $66^{\circ}-246^{\circ}$, $51^{\circ}-231^{\circ}$ e $81^{\circ}-261^{\circ}$, na data de $8 / 11 / 2006$ (dia com insolação de 10,4 horas).

Em regiões de baixas temperaturas noturnas seguidas de dias ensolarados, é comum o plantio de cafeeiro em linhas com sentido N-S em função da topografia do terreno, aumentando-se com isso a interceptação da radiação solar na face oeste à tarde, período em que a taxa fotossintética é normalmente reduzida (ChAves, 2005). Segundo ARAújo (2006) e DiAs (2006), as folhas superiores da face leste interceptam mais radiação nas primeiras horas do dia, enquanto as folhas superiores da face oeste interceptam mais RFA depois do meio-dia. 
O alinhamento $81^{\circ}-261^{\circ}$ tem a linha de plantio com maior proximidade do alinhamento $W-E$, permitindo maior autossombreamento entre os cafeeiros na linha em função do movimento aparente do Sol desde o nascente até o poente; este movimento ocorria quase acompanhando o alinhamento $81^{\circ}-261^{\circ}$, e com isso, um cafeeiro sombreava o outro na linha. Esse fato pode ter favorecido seu melhor desenvolvimento por ser considerada uma planta de sombra, pois neste caso provavelmente se dispunha de mais radiação solar difusa entre os cafeeiros. Este autossombreamento foi menos intenso nos demais alinhamentos, respectivamente, no $66^{\circ}-246^{\circ}$ e $51^{\circ}-231^{\circ}$. $\mathrm{O}$ autossombreamento foi notado nas observações de campo (Figuras 1 e 4 ).

O cafeeiro, originário de ambientes sombreados, exibe baixas taxas fotossintéticas, e portanto, nas folhas expostas ao sol pode exceder facilmente $600-700 \mu \mathrm{mol} \mathrm{m} \mathrm{m}^{-2} \mathrm{~s}^{-1}\left(130-152 \mathrm{~W} \mathrm{~m}^{-2}\right)$, valor que satura a fotossíntese nessas folhas, pois o cafeeiro exibe atributos típicos de planta de sombra (DaMatta, 2004; Silva et al., 2004). Em folhas da parte superior da copa, a RFAint varia de 50 a $1400 \mu \mathrm{mol} \mathrm{m}^{-2} \mathrm{~s}^{-1}$ (11 a $\left.304 \mathrm{~W} \mathrm{~m}^{-2}\right)$, enquanto para as inferiores varia de 20 a $800 \mu \mathrm{mol} \mathrm{m}^{-2} \mathrm{~s}^{-1}(4$ a $174 \mathrm{~W} \mathrm{~m}^{-2}$ ) (ARAújo, 2006).

Pela figura 5A, nos valores médios diários da RgI, RFAI e RFAint, observa-se que os valores de RgI variaram entre 15,7 e $23,1 \mathrm{MJ} \mathrm{m}^{-2}$ e de RFAI variaram entre 7,7 e 11,3 $\mathrm{MJ} \mathrm{m}^{-2}$. Os valores de RFAint também variaram proporcionalmente com os da RFAI, em função da sua dependência, com valores entre 4,6 e $8,56 \mathrm{MJ} \mathrm{m}^{-2}$. Nota-se que houve diminuição nas RFAint em todos os alinhamentos no período entre 20/12/06 e 13/2/07, devido à menor radiação solar global no período, pois neste período ocorreram as maiores quantidades de chuva e os menores valores de insolação. Em termos médios, os alinhamentos $66^{\circ}$ $246^{\circ}, 51^{\circ}-231^{\circ}$ e $81^{\circ}-261^{\circ}$ proporcionaram, respectivamente, $6,2 \mathrm{MJ} \mathrm{m}^{-2}, 5,9 \mathrm{MJ} \mathrm{m}^{-2}$ e 7,5 $\mathrm{MJ} \mathrm{m}^{-2}$ de RFAint, indicando que o alinhamento $81^{\circ}-261^{\circ}$ foi o que mais interceptou a RFA devido ao seu valor maior de $\operatorname{IAF}(2,28)$.

Pesquisadores, como Shibles e Weber (1965), JAHN (1979), FléNet et al. (1996), MAdDONNi e Otegui (1996), Collino et al. (2001) e Silva et al. (2006) constataram que a atenuação de radiação solar é função do IAF, e assim, o aumento da RFAint está sempre relacionada com o aumento de IAF. A quantidade de radiação solar interceptada e absorvida no dossel é dependente de vários fatores físicos e biológicos, como a posição solar, geometria, tamanho, anatomia e idade da folha, arranjo e estrutura das plantas (Pereira et al., 1982).
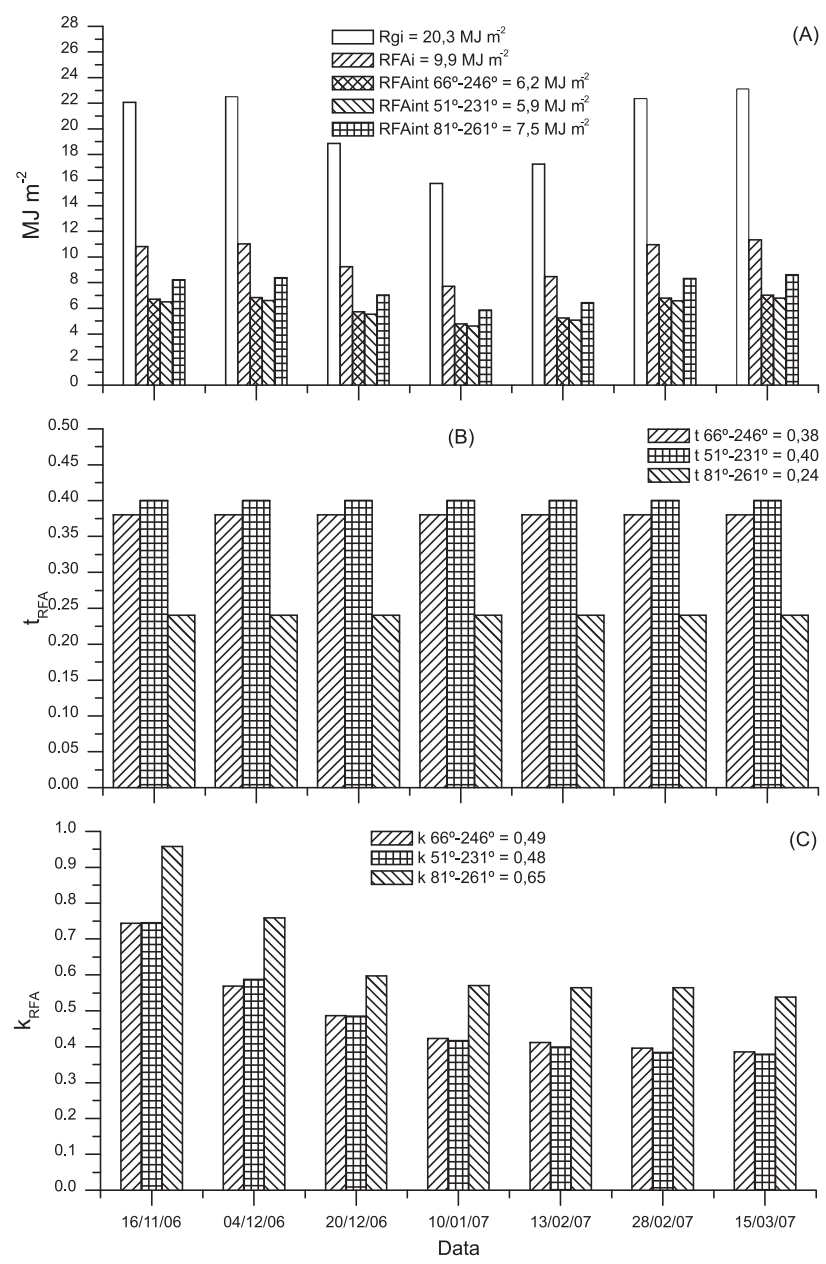

Figura 5. Radiação global (RgI), radiação fotossinteticamente ativa acima do dossel (RFAI) e interceptada abaixo do terço superior (RFAint) da copa de cafeeiro (A); coeficiente de transmissão $\left(t_{R F A}\right)$ no terço superior da copa (B); coeficiente de extinção da radiação fotossinteticamente ativa $\left(\mathrm{k}_{\mathrm{RFA}}\right)$ abaixo do terço superior da copa (C), nos alinhamentos $66^{\circ}-246^{\circ}, 51^{\circ}$ $231^{\circ}$ e $81^{\circ}-261^{\circ}$.

Pela figura 5B, nota-se que em todas as datas analisadas, no alinhamento $81^{\circ}-261^{\circ}$ ocorreu o menor coeficiente de transmissão $\left(t_{\mathrm{RFA}}\right)$ com valor médio de 0,24, indicando que, em média, $76 \%$ da RFAI foi interceptada pelo terço superior da copa do cafeeiro nesta orientação. Os maiores valores de $t_{\mathrm{RFA}}$ foram nos alinhamentos $51^{\circ}-231^{\circ}$ e $66^{\circ}-246^{\circ}$, com respectivos valores médios de 0,40 e 0,38 , mostrando que a copa desses alinhamentos interceptaram, respectivamente, $60 \%$ e $62 \%$ da RFAI.

Pela figura 5C representa a variação do coeficiente de extinção da radiação fotossinteticamente ativa $\left(\mathrm{k}_{\mathrm{RFA}}\right)$. Nota-se que ao longo do período analisado, o $\mathrm{k}_{\mathrm{RFA}}$ diminui em função do aumento do IAF do terço superior da copa de cafeeiro em todos os alinhamentos. Esse fato ocorre porque a interceptação da RFA está diretamente relacionada ao 
IAF da cultura (Shibles e Weber, 1965), pois o fluxo de radiação diminui de forma exponencial com o incremento de área foliar dentro do dossel (Robledo,1996; VAsconcelos et al., 2001).

Nota-se no alinhamento $81^{\circ}-261^{\circ}$ o maior valor do $k_{R F A}$, em média 0,65 , seguido pelos alinhamentos $66^{\circ}$ $246^{\circ}$ de 0,49 e $51^{\circ}-231^{\circ}$ de 0,48 , indicando que no alinhamento $81^{\circ}-261^{\circ}$ o terço superior da copa de cafeeiro foi mais eficiente no uso da RFA em relação aos outros alinhamentos. MARIN et al. (2003) constaram para o cafeeiro valores entre 0,79 e 0,82 para $\mathrm{k}_{\mathrm{RFA}}$ nas camadas que correspondem ao terço superior da copa, sendo as camadas superiores as que têm os maiores valores.

Sinclair e Horie (1989) verificaram que em baixo IAF a eficiência de uso da radiação pelo cafeeiro é reduzida, pois a maioria das folhas está sujeita à saturação fotossintética por radiação. Como a fração de AF sombreada aumenta com o decorrer do ciclo da cultura, aumenta também a eficiência de uso da radiação, e, assim aumenta a fração difusa, dando maior uniformidade da radiação no interior do dossel.

A taxa fotossintética e a densidade de fluxo de radiação não têm uma relação linear no interior do dossel do cafeeiro, pois a maioria das folhas está exposta a baixas intensidades de radiação. $\mathrm{O}$ aumento de $\mathrm{AF}$ sombreada com o decorrer do ciclo da cultura melhora a eficiência de uso da radiação até um determinado limite, em função do incremento das folhas sombreadas para o acúmulo de biomassa da cultura. Neste processo, outros fatores interferem, tais como, geometria e tamanho da folha, idade, arquitetura e arranjo das plantas, posição solar, época do ano e nebulosidade (VARLETGRANCHER et al., 1989), além das condições nutricionais, disponibilidade de água no solo, condições meteorológicas e práticas de manejo da cultura.

O conhecimento de relações entre variáveis agrometeorológicas e índices de crescimento possibilitam avaliar melhor uma determinada espécie ao longo de seu desenvolvimento, e assim, inferir diagnósticos em relação às condições de crescimento desta espécie analisada. Com esse intuito, correlacionou-se IAF versus $\mathrm{k}_{\mathrm{RFA}}$ (Figura 6A), e IAF versus RFAint acumulada ao longo de todo o período analisado (Figura 6B), para o terço superior da copa de cafeeiro para os alinhamentos $66^{\circ}-246^{\circ}, 51^{\circ}-231^{\circ}$ e $81^{\circ}-261^{\circ}$.

O modelo exponencial decrescente descreveu a diminuição do $k_{\text {RFA }}$ em função do IAF: $y$ é k RFA $_{\text {em }}$ função do IAF, sendo $A, B$ e $C$ parâmetros do modelo, em que $B$ é o valor máximo do IAF para um valor mínimo de $\mathrm{k}_{\mathrm{RFA}} ; x$ o IAF, e $C$ o valor de decaimento quase constante da curva, pois $C \cong 1$. O modelo mostra que na medida em que o IAF aumenta o $\mathrm{k}_{\mathrm{RFA}}$ diminui em função da relação RFAt/RFAI, pois RFAt diminui.
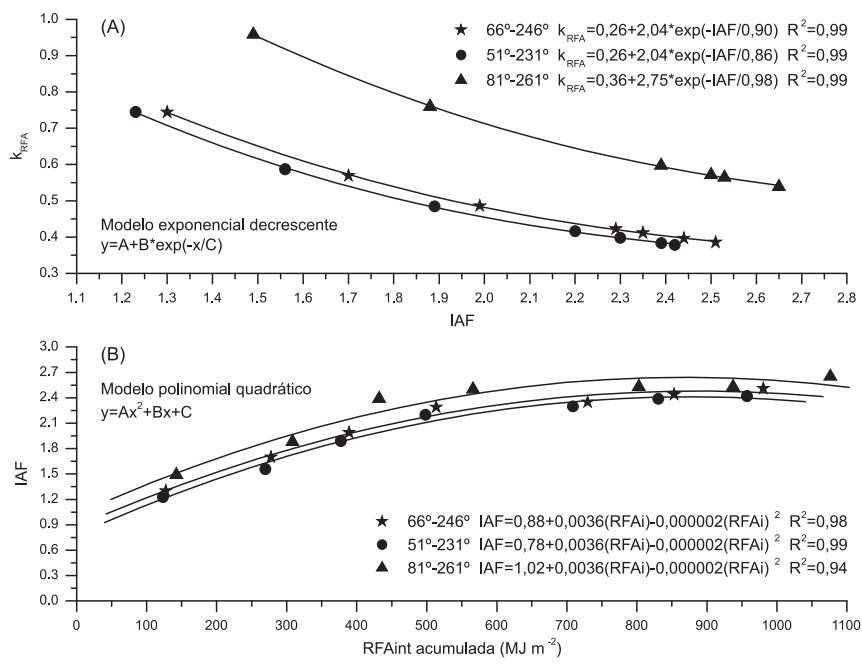

Figura 6. Relações entre o $\mathrm{k}_{\mathrm{RFA}}$ e o IAF do terço superior da copa de cafeeiro (A); relações entre o IAF e a RFA interceptada acumulada no terço superior da copa (B), nos alinhamentos $66^{\circ}-246^{\circ}, 51^{\circ}-231^{\circ}$ e $81^{\circ}-261^{\circ}$.

A correlação entre IAF e RFAint acumulada foi descrita pelo modelo polinomial quadrático para cada alinhamento, descrevendo o aumento do IAF em função da RFAint, em que o parâmetro $A$ indica a concavidade da curva, quando negativo indica concavidade para baixo. Assim, é possível determinar o ponto de máximo para as curvas por meio da equação: $x_{v}=-B / 2 A$. Nos três modelos o ponto de máximo é igual $\left(900 \mathrm{MJ} \mathrm{m}^{-2}\right)$. Substituindo o valor máximo de RAFint, temos os valores máximos de 2,5; 2,4 e 2,6 para o IAF, superestimando os valores medidos em $19 \%, 20 \%$ e $13 \%$, respectivamente, para os alinhamentos $66^{\circ}-246^{\circ}$, $51^{\circ}-231^{\circ}$ e $81^{\circ}-261^{\circ}$ (Figura $6 \mathrm{~B}$ ).

Os valores 0,$88 ; 0,78$ e 1,02 , o parâmetro $C$ do modelo, respectivamente, para os alinhamentos $66^{\circ}$ $246^{\circ}, 51^{\circ}-231^{\circ}$ e $81^{\circ}-261^{\circ}$, indica a interseção no eixo $y$, ou seja, o ponto inicial do IAF para um valor de RFAint $=0$, pois o terço superior do cafeeiro parte de um valor inicial de IAF independente da medida de RFAint, pois o cafeeiro já possuía área foliar quando se iniciaram as medidas no terço superior da copa (Figura 6B).

A tendência de aumento linear e quadrático do IAF vai até os $900 \mathrm{MJ} \mathrm{m}^{-2}$, e a partir daí o decréscimo ocorre devido à senescência das folhas. Nota-se que em todas as curvas há a mesma forma, dando-se preferência ao modelo do alinhamento $81^{\circ}$ $261^{\circ}$, em função de ter superestimado menos o IAF (Figura 6B).

Pesquisadores como França et al. (1999) e SCHÖFfEl e VOLPE (2001) também ajustaram o modelo polinomial quadrático para a correlação entre IAF e RFAint. 


\section{CONCLUSÕES}

1. O índice de área foliar e a radiação fotossinteticamente ativa interceptada, medidas no terço superior da copa de cafeeiro variedade Obatã variam em função dos alinhamentos de plantio, e consequentemente, variam também os coeficientes de transmissão e de extinção.

2. O alinhamento $81^{\circ}-261^{\circ}$, por ser o que mais se aproxima do movimento aparente do Sol desde o nascente até o poente, favorece um autossombreamento maior na linha e, assim, ocorre maior disponibilidade de radiação solar difusa, contribuindo para maior índice de área foliar.

3. Os coeficientes de transmissão são menores e os de atenuação são maiores para o alinhamento $81^{\circ}$ $261^{\circ}$, mostrando maior eficiência na interceptação da radiação fotossinteticamente ativa no terço superior da copa desse alinhamento.

4. É possível estimar o coeficiente de extinção em função do índice de área foliar por meio de modelo exponencial, e estimar o índice de área foliar em função da radiação fotossinteticamente ativa interceptada pelo modelo polinomial quadrático, no terço superior da copa de cafeeiro.

\section{AGRADECIMENTOS}

À Fundação de Amparo à Pesquisa do Estado de São Paulo (FAPESP) pela bolsa de Pós-Doutorado concedida para a realização do referido trabalho (Processo n ${ }^{\circ}$ 05/59535-4).

\section{REFERÊNCIAS}

ARAÚJO, W.L. Limitações da fotossíntese e metabolismo do carbono em folhas de diferentes posições da copa do cafeeiro (Coffea arabica L.). 2006. 43p. Dissertação (Mestrado em Fisiologia Vegetal) - Universidade Federal de Viçosa, Viçosa.

BARROS, R.S.; MAESTRI, M.; VIEIRA, M.; BRAGA-FILHO, L.J. Determinação de área de folhas do café (Coffea arabica L. cv. 'Bourbon Amarelo'). Revista Ceres, v.20, p.44-52, 1973.

BENINCASA, M.M.P. Análise do crescimento de plantas: noções básicas. 1. ed. Jaboticabal: FUNEP, 1988. 42p.

BERNARDES, M.S.; CASTRO, P.R.C.; MARTINS, A.N Formação da copa e resistência de árvores ao vento: modelo de seringueira. Piracicaba: FEALQ, 1996. 88p.

CAMARGO, A.P.; CAMARGO, M.B.P. Definição e esquematização das fases fenológicas do cafeeiro arábica nas condições tropicais do Brasil. Bragantia, v.60, p.6568, 2001.
CANNELL, M.G.R. Crop physiological aspects of coffee bean yield: a review. Kenya Coffee, v.41, p.245-253, 1976.

CHAVES, A.R.M. Fotossíntese e mecanismos de proteção contra estresse fotooxidativo em Coffea arabica L., cultivado em condições de campo sob dois níveis de irradiância. 2005. 36p. Dissertação (Mestrado em Fisiologia Vegetal) Universidade Federal de Viçosa, Viçosa.

COLLINO, D.J.; DARDANELLI, J.L.; SERENO, R.; RACCA, R.W. Physiological responses of argentine peanut varieties to water stress. Light interception, radiation use efficiency and partitioning of assimilates. Field Crops Research, v.70, p.177184, 2001.

DAMATTA, F.M. Drought as a multidimensional stress affecting photosynthesis in tropical tree crops. In: HEMANTARANJAN, A. (Ed.). Advances in Plant Physiology. Scientific Publishers: Jodhpur, 2003. p.227-265.

DAMATTA, F.M. Ecophysiological constraints on the production of shaded and unshaded coffee: a review. Field and Crops Research, v.86, p.99-114, 2004.

DIAS, P.C. Variação espacial da fotossíntese e de mecanismos de fotoproteção no cafeeiro (Coffea arabica L.). 2006. 34p. Dissertação (Mestrado em Fisiologia Vegetal) - Universidade Federal de Viçosa, Viçosa.

FERNANDES, A.L.T.;SANTINATO, R.; PEREIRA, E.M.;SILVA, V.A. Efeitos do direcionamento Norte-Sul (NS), Leste-Oeste (LO), Nordeste-Sudeste (NO-SL) e Noroeste-Sudoeste (NL-SO) das linhas de plantio do cafeeiro nos altiplanos do cerrado com altitudes superiores a $900 \mathrm{~m}$. In: CONGRESSO BRASILEIRO DE PESQUISAS CAFEEIRAS, 27., 2001, Uberaba. Anais... Rio de Janeiro: Mapa/Procafé, 2001.

FRANÇA, S.; BERGAMASCHI, H.; ROSA, L.M.G. Modelagem do crescimento de milho em função da radiação fotossinteticamente ativa e do acúmulo de graus-dia, com e sem irrigação. Revista Brasileira de Agrometeorologia, v.7, p.59-66, 1999.

FLÉNET, F.; KINIRY, J.R.; BOARD, J.R.; WESTGATE, M.E.; REICOSKY, D.C. Row spacing effects on light extinction coefficients of corn, sorghum, soybean and sunflower. Agronomy Journal, v.88, p.185-190, 1996.

FREITAS, E.D. Apostila de agrometeorologia: fundamentos de ecofisiologia aplicada. São Paulo: Departamento de Ciências Atmosféricas - IAG/USP, 2005. 145p.

GALLO, K.P.; DAUGHTRY, C.S.T.; WIEEGAND, C.L. Errors in measuring absorbed and computing crop radiation use efficiency. Agronomy Journal, v. 85, p.1222-1228, 1993.

GLIESSMAN, R.S. Agroecologial: processos ecológicos em agricultura sustentável. Porto Alegre: Ed. Universidade Rio Grande do Sul, 2000. 182p.

HUERTA, S.A.; ALVIM, P.T. Indice de area foliar y su influencia en la capacidad fotosintetica del cafeto. Cenicafé, Chinchina, v.13, p.75-84, 1962. 
JAHN, O.L. Penetration of photosynthetically active radiation as a measurement of canopy density of citrus tress. Journal American Horticultural Science, v.4, p.557-560, 1979.

JONES, H.G. Plants and microclimate: a quantitative approach to environmental plant physiology. Cambridge: Cambridge University Press, 1994. 428p.

MADDONNI, G.A.; OTEGUI, M.E. Leaf area, light interception and crop development in maize. Field Crops Research, v.48, p.81-87, 1996.

MARIN, F.R.;SANTIAGO, A.V.; RIGHI, E.Z.; SENTELHAS, P.C.; ANGELOCCI, L.R.; MAGGIOTTO, S.R.; PEZZOPANE, J.R.M. Solar radiation interception and its relation with transpiration in different coffee canopy layers. Revista Brasileira de Agrometeorologia, v.11, p.1-6. 2003.

PARTELLI, L.F.; VIEIRA, H.D.; VIANA, A.P. Estimativa da área foliar do cafeeiro conilon a partir do comprimento da folha. Revista Ceres, v.53, p.204-210, 2006.

PEREIRA, A.R.; MACHADO, E.C.; CAMARGO, M.B.P. Solar radiation regime in three cassava (Manihot esculenta Crantz) canopies. Agricultural Meteorology, v.26, p.1-10, 1982.

POMPELLI, M.F. Respostas anatômicas e fisiológicas de plantas de café cultivadas em diferentes níveis de nitrogênio e irradiância. 2008. Tese (Doutorado em Fisiologia Vegetal) Universidade Federal de Viçosa, Viçosa.

ROBLEDO, A.J. Aspectos microclimáticos en plantaciones de café (Coffea arabica L.) com alta densidad de siembra. In: SIMPÓSIO INTERNACIONAL SOBRE CAFÉ ADENSADO, 1. 1994, Londrina. Anais... Londrina: IAPAR, 1996. p.47-69.

SCHÖFFEL, E.R.; VOLPE, C.A. Eficiência de conversão da radiação fotossinteticamente ativa interceptada pela soja para a produção de fitomassa. Revista Brasileira de Agrometeorologia,v.9, p.241-249. 2001.

SHIBLES, R.M.; WEBER, C.R. Leaf area, solar radiation and dry matter production by soybeans. Crop Science, v.5, p.575$577,1965$.

SILVA, E.A.; DAMATTA, F.M.; DUCATTI, C.; REGAZZI, A.J.; BARROS, R.S. Seasonal changes in vegetative growth and photosynthesis in Arabica coffee trees. Field Crops Research, v.89, p.349-357. 2004.

SILVA, W.J.; VOLPE, C.A. Crescimento do fruto do cafeeiro (Coffea arábica L.) cv. Acaiá, CP 474/19 e suas relações com variáveis meteorológicas em dois sistemas de plantio, no cerrado de Uberaba-MG. Revista Brasileira de Agrometeorologia, v.13, p.292-302, 2005.

SILVA, P.R.F.; SANGOI, L.; ARGENTA, G.; STRIEDER, M.L. Importância do arranjo de plantas na definição da produtividade do milho. Porto Alegre: UFRGS - Evangraf, 2006. 65p.

SINCLAIR, T. R.; HORIE, T. Leaf nitrogen, photosynthesis, and crop radiation use efficiency: a review. Crop Science, v.29, p. $98-105,1989$.
TAVARES JUNIOR., J.E; FAVARIN, J.L.; DOURADO-NETO, D.; MAIA, A.H.N.; FAZUOLI, L.C.; BERNARDES, M.S. Análise comparativa de métodos de estimativa de área foliar em cafeeiro. Bragantia, v.61, p.199-203, 2002.

VARLET-GRANCHER, C.; GOSSE, G.; CHARTIER, M.; SINOQUET, H.; BONHOMME, R.; ALLIRAND, J. M. Mise au point: rayonnement solaire absorbé ou intercepté par un couvert végétal. Agronomie, v.9, p. 419-439, 1989.

VASCONCELOS, R.C.; SOUZA, C.A.S.; DIAS, F.P.; GUIMARÃES, R.J. Cultivo do cafeeiro em condições de adensamento. Lavras: UFLA, 2001. 43p. (Boletim de Extensão) 